\title{
Revista História Oral: um auto-olhar
}

EM DIFERENTES PAÍsES onde a história oral tem se instalado, passados alguns anos, nota-se um esforço analítico voltado ao processo que ditou a origem e o desenvolvimento da matéria naquele espaço e tempo. A repetição deste procedimento no Brasil permite algumas observações que costuram em um mesmo tecido a necessidade de auto-reflexão e a afirmação dessa área em face da comunidade nacional e internacional. ${ }^{1}$ Encontros, congressos, conferências, comunicações, artigos e teses trazem, inevitavelmente, alguma manifestação afeita a essa gênese que, afinal, equivale às explicações dos usos da oralidade em diferentes círculos e com diversos fins.

Como que garantindo uma historicidade onde, de regra, a história oral é considerada recurso duvidoso, o "auto-olhar" da comunidade - que usufrui desta prática, talha um corpo que precisa ser definido e reafirmado constantemente, face às forças de resistência externas. Em particular, para os adeptos da história oral, a exibição dos resultados, bem como os fundamentos de sua prática, se fazem degrau para justificar a validade do recurso que percorre um trajeto que vai de mero registro a instrumental analítico.

Pode-se dizer que existem dois principais pólos que sugerem eventuais publicações de história oral. Em uma ponta a comunidade imediata, interessada apenas na divulgação de resultados espontâneos pertinentes ao próprio grupo. Em outra, trabalhos mais sofisticados aspiram avanços que não prescindem do debate teórico e de vínculos historiográficos. No primeiro caso, as intenções são modestas em termos de discussão metodológica e enquadramento temático e, para eles, a divulgação poucas vezes excede o limite do consumo interno, comportado nos desejos informativos de registros de algumas experiências

1 Autores estrangeiros reconhecem que, como diz textualmente Alessandro Portelli, "há pelo menos dez anos, o Brasil está na vanguarda neste campo, no plano internacional" (2002, p. 9). 
contextualizadas em área restrita. Para suprir tais anseios proliferam os catálogos de coleções e as notícias de pesquisas vinculadas aos grupos imediatos, instituições ou mostras e exposições específicas.

No plano amplo, porém, os efeitos ambicionados são outros, pois a base teórica e o efeito do impacto temático em contextos maiores impõem a aceitação do papel da história oral como recurso de uso técnico ou metodológico para as ciências humanas. Neste caso, atualização teórica, fundamentação historiográfica, articulação com áreas específicas de estudos se fazem condição para o desenvolvimento de pesquisas que se engajam em discussões e debates complexos. Sendo que a história oral ainda não tem um campo próprio definido que a estabeleça como disciplina, os diferentes aportes relativos aos usos nos diversos espaços do conhecimento reclamam, de saída, explicações competentes e construídas em nível acadêmico. Daí a necessidade de revistas especializadas que divulguem estudos afins e proponham discussões cabíveis.

Por uma ou por outra via, porém, destaca-se o complexo debate sobre os níveis institucionalizadores da história oral. É nesta perspectiva que se busca traçar a história da revista História Oral, da Associação Brasileira de História Oral que caminha para seus dez anos de vida. Instituição feita, a $\mathrm{ABHO}$ propôs vias comunicativas das quais uma das mais importantes é a nossa revista. Outra, o Boletim História Oral, iniciado já na primeira gestão, de caráter informativo, que tem um importante papel como elemento divulgador e agregador da Associação. Os primeiros números eram em forma impressa, hoje funcionando eletronicamente.

A institucionalização da história oral ligou-a ao mundo acadêmico, deixando de ser uma manifestação espontânea, livre, filha independente de desejos de grupos mais ou menos fechados, como: migrantes ou imigrantes, associações de trabalho ou religiosas, clubes de lazer ou de defesa de interesses dos próprios membros. Quando se procede à reflexão sobre o "outro" pela história oral, passa-se do nível da observação para o nível analítico.

Aliás, é para controlar o teor emocional e para possibilitar diálogos com outros estudos afins e critérios intelectuais estabelecidos que o "rigor acadêmico" se coloca e justifica no uso da história oral. No horizonte do ideal, uma postura não deveria excluir a outra, ainda que, 
quase fatalmente, os critérios de institucionalização admitam a aproximação de entre um tipo de história oral espontâneo, amador, e outro que se fundamenta até profissionalmente. ${ }^{2}$

As publicações associativas, como é o caso da revista História Oral, revelam a intenção de um projeto institucional. Nesta direção, o juízo crítico com compromissos teóricos extrai a vivência da história oral do limite da aventura despretensiosa, do mero registro de grupos preocupados apenas com a coleta de elementos mantenedores da questão que os levou ao uso da oralidade. A sistematização em um veículo difusor de debates propicia a acumulação, modelos e avanços que se operam sobretudo em diálogos teóricos. A revista História Oral dimensiona o sucesso da $\mathrm{ABHO}$, como foi textualmente fixado no primeiro número da publicação que há seis anos passados dizia:

"desde a semente lançada em 1992, a proposta do que seria mais tarde, em 1994, a Associação Brasileira de História Oral (ABHO) alimentou o sonho que hoje se materializa nesta revista História Oral. Pode-se dizer que o mesmo impulso criador gerou ambas. A ABHO e a revista, portanto, se relacionam como resultado do mesmo processo. Mãe e filha, as duas "geracionam" etapas de desenvolvimento de uma proposta que se exibe publicamente triunfante.” (Meihy, 1998, p. 7)

O número inaugural de História Oral arrolou explicações que remontam à criação da $\mathrm{ABHO}$ em 1994 e à intimidade do vínculo com a revista, cujo primeiro número foi editado em $1998 .^{3}$ O então presidente da Associação, Antônio Montenegro, retomando a trajetória da instituição aliou uma pequena série de publicações anteriores que atestam

2 Muitos estudos locais têm sustentação acadêmica e paradoxalmente, nem toda manifestação feita na universidade responde aos anseios teóricos e metodológicos supostos.

3 Ainda que a $\mathrm{ABHO}$ tenha sido criada apenas em 1994, desde 1993 realizaram-se os chamados "encontros nacionais de história oral". A gênese da Associação está ligada ao encontro promovido durante o Congresso Internacional América 92, raízes e trajetórias, promovido pelo Departamento de História da USP em agosto de 1992. Nesta ocasião foi proposto o I Encontro Nacional, que se realizou na USP graças ao empenho de Alice Beatriz da Silva Gordo Lang (CERU), Yara Aun Khoury (PUC/SP) e José Carlos Sebe Bom Meihy (USP). 
a tensão então existente em favor da criação de uma revista da própria entidade. Chamando a atenção para os liames entre o resultado de trabalhos apresentados em encontros da $\mathrm{ABHO}$ e alguns textos que se preocuparam em preencher a lacuna de publicações sistemáticas, Montenegro indicou três livros que podem ser considerados antecessores diretos de História Oral, a saber:

- História Oral, organizado por Marieta de Moraes, com textos expostos no II Encontro de História Oral, realizado no CPDOC, em 1994 (Ferreira, 1994);

- Re)introduzindo história oral no Brasil, organizado por José Carlos Sebe Bom Meihy com base nas comunicações apresentadas no I Encontro Regional de História Oral (regiões sul/sudeste), realizado no Departamento de História da USP em 1995 (Meihy, 1996);

- Os desafios contemporâneos da história oral, organizado por Olga Rodrigues de Moraes von Simson, com textos recolhidos no III Encontro Nacional de História Oral, realizado na UNICAMP, em maio de 1996 (Simon, 1997).

É importante notar que estas publicações derivaram dos principais pólos promotores da ABHO: USP, CPDOC, CERU, PUC-SP e UNICAMP. Mérito da História Oral a oportunidade de incluir trabalhos de outras regiões do Brasil e, assim, alargar os espaços integradores da ABHO.

Situando a origem da $\mathrm{ABHO}$ como divisor de águas, questionase o efeito da herança anterior. Até seu surgimento, quais teriam sido os avanços propostos em termos da trajetória da história oral no Brasil? Quais os principais encaminhamentos capazes de promover a institucionalização materializada na $\mathrm{ABHO}$ ? As respostas a estas questões sugerem que sejam levados em conta debates sobre as referidas publicações e também elencados textos que poderiam ser cotados como "fundadores" da história oral no Brasil.

Definindo que o primeiro escrito publicado a usar o termo "história oral" no Brasil foi assinado por Carlos Humberto Correa, em 1978, tem-se então as demais alternativas vinculadas à paternidade da história oral no Brasil (Correa, 1978). Antes de Correa, autores importantes se referiram ao uso de "depoimentos pessoais" vinculados às "histórias de vida" e, neste sentido, a semente mãe decorre de Maria Isaura Pereira de Queiroz que, em 1953, publicou o importante texto 
Histórias de vida e depoimentos pessoais (Queiroz, 1953). Pereira de Queiroz, fecundando a linha sociológica introduzida por Roger Bastide na USP, desdobrou reflexões teóricas que foram difundidas ao longo dos anos pelos membros do Centro de Estudos Rurais e Urbanos (CERU). ${ }^{4}$

Paralelamente ao florescimento de uma linha difundida por Pereira de Queiroz, outros pólos implementaram no Brasil o uso da história oral. Com maior sucesso, no Rio de Janeiro, o Grupo de Documentação em Ciências Sociais - GDCS, através de um de seus subgrupos, propôs o I Curso de História Oral, levado a efeito em 1975, com o patrocínio da CAPES e da Fundação Ford. ${ }^{5}$ Com resultados atomizados e revertidos em benefícios das próprias instituições participantes, o maior sucesso se fez no CPDOC, que aos poucos se impôs como centro de referência.

A fragmentação do grupo original que freqüentou o I Curso desfez caminhos coletivos, embora fosse levado a efeito outro encontro, em 1977, em Brasília. Ainda que alguns projetos de laboratórios de história oral se fizessem, o único a merecer destaque nacional foi o do CPDOC por duas razões somadas: um claro projeto de trabalho com as elites - compatível com propostas emanadas do poder estabelecido - e a contribuição substancial da Fundação Ford (D'Araújo, 1999, p. 178, n. 6)

$\mathrm{O}$ ambiente de abertura política, definido principalmente depois de 1979 com a Anistia, motivou a aventura da história oral que assim compatibilizava seu (re)surgimento com a anunciada democratização. Nos anos da década de 1980, cresciam as propostas de recolhas e análises de entrevistas e se articulavam pesquisas repontadas em diversos quadrantes do país. Apenas na década de 1990, porém, iniciavam-se publicações de âmbito nacional. Neste sentido, aliás, caracterizaram-se os dois pontos cruciais da crítica aos projetos anteriores de história oral no Brasil: a inviabilidade social de florescimento em ambiente não democrático, a motivação provocada por agências estrangeiras e a falta de

4 Nesta linha vale a pena considerar o conjunto de textos reunidos na publicação Variações Sobre a Técnica de Gravador no Registro da Informação Viva (1991).

5 O grupo, coordenado pelo CPDOC, era composto das seguintes entidades: Universidade Federal Fluminense, Universidade de Brasília, Universidade Federal de Santa Catarina e do Centro de Memória Social Brasileira. Sobre o assunto leia-se o texto de Marieta de Moraes Ferreira "História Oral e Tempo Presente" (1996, p. 12) 
adesão pública de grupos capazes de consumir trabalhos que fossem compatíveis com os anseios democratizantes. $\mathrm{O}$ avesso desta questão, por outro lado, interessa sobremaneira: uma legítima história oral nascia no exílio. Sem dúvidas, os dois primeiros textos não teóricos, comprometidos com o sentido do tempo da Abertura Política, que refletem o papel da cultura do tempo - e que justifica uma democrática mudança nos rumos da produção documental e da análise de dados decorrentes de entrevistas - são: Memórias do Exílio, de Pedro Celso Uchoa Cavalcanti e Jovelino Ramos (1976), e Memórias das Mulheres no Exílio, de Albertina de Oliveira Costa et al (1980).

Duas iniciativas importantes na década de 80 foram a publicação dos resultados da mesa redonda organizada por Eva Alterman Blay Histórias de vida: problemas metodológicos da investigação e da análise durante o X Encontro Nacional de Estudos Rurais e Urbanos em 1983 e o livro Getúlio Vargas, uma história oral (1986), resultante de pesquisa realizada pelo Programa de História Oral do CPDOC, coordenado por Valentina da Rocha Lima.

Outra marca do período mais recente - muito pouco notada - é que a carência de uma história oral decorrente da naturalidade do meio social implicou um colonialismo comum a outros países latino-americanos, onde o lapso de continuidade gerou uma prática de importação de modelos que muitas vezes mostram-se postiços aos nossos interesses. ${ }^{7}$

Com o primeiro número lançado em 1998, História Oral viria suprir a carência de uma publicação periódica voltada a segmentos especializados. Com nítida preocupação com aspectos metodológicos, temáticos, multidisciplinares e com a divulgação de textos capitais de autores estrangeiros, a Revista pontua também a referenciação histórica em avaliações da própria trajetória. Neste sentido, aliás, é válido salientar que além da natural abordagem sobre sua gênese, apresentada no número 1, os conteúdos dos números subseqüentes de História Oral

6 Resultados publicados em Cadernos CERU, 19, 1984, com textos de Carlos Rodrigues Brandão, Guita Grin Debert, e Aspásia Camargo, Valentina da Rocha Lima e Lúcia Hipólito.

7 Este assunto foi levado à discussão no X Congresso Internacional de História Oral, realizado no Rio de Janeiro em 1998, e os papers de Janaina Amado, Dora Schwarzstein e José Carlos Sebe Bom Meihy foram publicados em: Ferreira, Marieta de Moraes (org.). História Oral: desafios para o século XXI. (2000). 
colocam dilemas que se reportam aos seguintes aspectos: existiria uma história oral brasileira coerente com os anseios da comunidade acadêmica nacional ou ela seria mero desdobramento de manifestações externas? Quais são as principais matrizes discursivas?

Uma história oral de caráter nacional responderia à construção dos principais dilemas de nossa sociedade, supondo temas e soluções técnicas e metodológicas advindas da realidade social que os gera. Muitas são as pesquisas sobre mestiçagem, herança cultural indígena ou africana, impacto da imigração e demais assuntos enquadrados no circuito da cultura brasileira. Certamente, não se despreza o diálogo com os avanços estrangeiros na área, pelo contrário, são até valorizados, principalmente quando propõem diálogos com questões que fazem ecos no Brasil. ${ }^{8}$

Um passeio pelos diversos números de História Oral permite notar algumas de suas características mais importantes: o cuidado com a definição da origem, a atenção teórica e metodológica, a abrangência territorial e a divulgação de textos estrangeiros pertinentes ao debate teórico interno. A constituição de dossiês reforça essa premissa.

A Revista foi estruturada em quatro sessões: um dossiê reunindo trabalhos sobre um determinado tema, mostrando formas diversas de tratá-lo; artigos divulgando trabalhos de pesquisadores ligados a instituições de pontos variados deste país de dimensões continentais; entrevistas que constituem uma forma privilegiada de obtenção de narrativas trabalhadas pela história oral e marcadas pela interação pesquisadorpesquisado e resenhas que dão a conhecer o conteúdo de livros recentemente publicados, que utilizaram a metodologia da História Oral.

Os dossiês cobrem as seguintes temáticas nos sucessivos números: Getúlio Vargas; violência e politica; memória e trabalho; narrativa e narradores; identidade e região; tempo e narrativa, chegando ao número atual com questões metodológicas. Quanto às entrevistas, foram realizadas com pessoas de atuação significativa na História Oral, com um profissional

8 Textos de autores como Dora Schwarzstein, Alistair Thomson, Mercedes Vilanova, entre outros, são estampados em nome de diálogos teóricos. Na mesma ordem, outra virtude de História Oral: autores que não tratam diretamente da matéria mas que de forma pertinente tangenciam os focos centrais do debate brasileiro convivem nas páginas de História Oral, entre outros cita-se Olgaria Matos, Edgar De Decca. 
de destaque na área acadêmica internacional, o historiador Jacques Revel e, neste número com o economista Celso Furtado.

Tratando-se de um delineamento histórico da Revista História Oral, importante se torna registrar os editores responsáveis pelos diversos números até hoje publicados, que a tornaram uma realidade, uma iniciativa que esperamos irreversível: José Carlos Sebe Bom Meihy, Ângela de Castro Gomes, Maria de Lourdes Monaco Janotti e Alice Beatriz da Silva Gordo Lang. A RHO conta com um Comitê Editorial e com o apoio do Conselho Editorial, responsável pela avaliação dos trabalhos encaminhados para publicação.

Em termos do cuidado com a definição de origem, além das " $\mathrm{Pa}$ lavras do Editor" no número 1 da revista (Meihy, 1998), Marieta de Moraes Ferreira assina os "Desafios e dilemas da história oral nos anos 90: o caso do Brasil" (1998). Dois outros registros, ambos entrevistas, se fazem importantes: no número 2, "Como a História Oral chegou ao Brasil: entrevista com Aspásia Camargo” (D’Araújo, 1999) e no número 4 "Entrevista com Marieta M. Ferreira" (Santana \& Alberti, 2001) que ressalta as raízes plurais da $\mathrm{ABHO}$.

Em face da atenção teórica, dois aspectos marcam a produção aferida pela RHO: memória e identidade. Com repetidas recorrências aos dois temas, a Revista evidencia uma tendência dos trabalhos brasileiros que assumem estes pólos como objeto de pesquisa.

A abrangência territorial é outra dimensão importante dos objetivos da História Oral, preocupada em abrir espaço para a publicação de trabalhos de autores de vários estados e instituições brasileiras.

Nos dez anos da ABHO, sem dúvidas, a revista História Oral tem ocupado lugar de destaque. Mais do que divulgar, integração é uma das metas das editorias que em diferentes tempos cuidam de provar que os dilemas que cercam a cultura acadêmica brasileira são matéria essencial da História Oral.

José Carlos Sebe Bom Meihy

Alice Beatriz da Silva Gordo Lang 


\section{Referências bibliográficas}

CAVALCANTI, Pedro Celso Uchoa; RAMOS, Jovelino. Memórias do exílio. São Paulo: Livramento, 1976.

CORREA, Carlos Humberto. História Oral: teoria e técnica. Florianópolis: Universidade Federal de Santa Catarina, 1978.

COSTA, Albertina de Oliveira et al. Memórias das mulheres no Exílio. Rio de Janeiro: Paz e Terra, 1980.

D'ARAÚJO, Maria Celina. Como a história oral chegou ao Brasil: entrevista com Aspásia Camargo. História Oral (2), jun. 1999.

FERREIRA, Marieta de Moraes (org.). História Oral. Rio de Janeiro: Diadorim Editora, 1994.

. História Oral e Tempo Presente. In: MEIHY, J.C.S.B. (Re)introduzindo história oral no Brasil. São Paulo: Ed. Xamã, 1996.

- Desafios e dilemas da história oral nos anos 90: o caso do Brasil. História Oral (1), p. 19-30, jun. 1998.

- (org.). História Oral: desafios para o século XXI. Rio de Janeiro: Casa de Oswaldo Cruz, 2000.

LIMA, Valentina da Rocha (org.). Getúlio: uma história oral. 2a ed. Rio de Janeiro: Record, 1986.

MEIHY, José Carlos Sebe Bom (org.). (Re)introduzindo história oral no Brasil. São Paulo: Ed. Xamã, 1996.

- Palavras do editor. História Oral (1), p. 7-9, jun. 1998.

PORTELLI, Alessandro. Apresentação. In: FREITAS, Sônia Maria de. História Oral: possibilidades e procedimentos. São Paulo: Humanitas, 2002.

QUEIROZ, Maria Isaura Pereira de. Histórias de vida e depoimentos pessoais. Sociologia, v. XV, n. 1, São Paulo, mar. 1953.

- Variações Sobre a Técnica de Gravador no Registro da InformaÇão Viva. São Paulo: CERU, 1983. Coleção Textos, N. 4. (2a Edição: São Paulo, T. A. Queiroz, 1991).

SANTANA, Marco Aurélio; ALBERTI, Verena. A IOHA na voz de suas presidnetes: entreivsta com Marieta M. Ferreira. História Oral (4), p. 165-76, jun. 2001.

SIMSON, Olga Rodrigues de Moraes von. Os desafios contemporâneos da História Oral - 1996. Campinas: CMU/UNICAMP, 1997. 